\title{
How does multimorbidity affect middle- aged adults? A cross-sectional survey in the Singapore primary healthcare setting
}

\author{
Sai Zhen $\operatorname{Sim}^{1 *}$ D, Hui Li Koh', Sabrina Poay Sian Lee ${ }^{1}$, Doris Yee Ling Young ${ }^{2}$ and Eng Sing Lee ${ }^{1}$
}

\begin{abstract}
Background: Multimorbidity is of increasing prevalence and importance. It has been associated with poorer healthrelated quality of life ( $\mathrm{HrQoL}$ ) especially in the elderly population. Despite substantial multimorbidity in the middleaged population, defined as those aged between 40-64 years old, there is a paucity of research investigating the impact of multimorbidity in this population. This study aimed to investigate the association between multimorbidity and HrQoL in the middle-aged primary care population in Singapore.
\end{abstract}

Methods: A cross-sectional study was conducted at a primary care centre in Singapore. Interviewer-administered questionnaires were used to collect data regarding the participants' sociodemographic characteristics, chronic conditions, and HrQoL, as measured by the EuroQol five dimensions 3-levels questionnaire (EQ5D). We defined multimorbidity as the presence of three or more conditions, out of a list of 14 chronic conditions. The associations between multimorbidity and the components of the EQ5D were assessed using multivariable regression analyses.

Results: The study included 297 participants, aged 40-64 years, of which 124 (41.7\%) had multimorbidity. After adjusting for sociodemographic factors, participants with multimorbidity had significantly lower EQ5D UI, ( $\beta$ coefficient $-0.064(C .1-0.125,-0.003), p=0.04)$, but not significantly lower EQ5D VAS, ( $\beta$-coefficient -0.045 (C.I $0.102,0.012), p=0.12)$. Additionally, participants with multimorbidity had higher odds $(\mathrm{OR}=2.41, p=0.01)$ of reporting problems due to pain/discomfort.

Conclusion: Multimorbidity was not significantly associated with the overall health state, as measured by the EQ5D VAS, in middle-aged primary care patients. However, it was associated with the EQ5D UI which is a composite measure of five specific domains of HrQoL. Specifically, there was a statistically significant association between multimorbidity and the pain domain. Further studies are required to understand the relationship between multimorbidity and pain to enable physicians to better manage pain and HrQoL in this population.

Keywords: Multimorbidity, Health-related quality of life, Sociodemographic, Middle-aged, Primary care

\footnotetext{
*Correspondence: sai_zhen_SIM@nhgp.com.sg

'Clinical Research Unit, National Healthcare Group Polyclinics, 3 Fusionopolis Link, Nexus@one-north. South Tower, \# 05-10, Singapore 138543, Singapore Full list of author information is available at the end of the article
}

(c) The Author(s). 2020 Open Access This article is licensed under a Creative Commons Attribution 4.0 International License, which permits use, sharing, adaptation, distribution and reproduction in any medium or format, as long as you give appropriate credit to the original author(s) and the source, provide a link to the Creative Commons licence, and indicate if changes were made. The images or other third party material in this article are included in the article's Creative Commons. licence, unless indicated otherwise in a credit line to the material. If material is not included in the article's Creative Commons licence and your intended use is not permitted by statutory regulation or exceeds the permitted use, you will need to obtain permission directly from the copyright holder. To view a copy of this licence, visit http://creativecommons.org/licenses/by/4.0/ The Creative Commons Public Domain Dedication waiver (http://creativecommons.org/publicdomain/zero/1.0/) applies to the data made available in this article, unless otherwise stated in a credit line to the data. 


\section{Background}

Multimorbidity, defined as the presence of multiple chronic conditions without a specific index disease, [1] is prevalent in primary care $[2,3]$. About 30 to $58 \%$ of middle-aged patients have multimorbidity, [2-4] and the absolute number of these patients may even exceed that of elderly patients [3]. A survey of the general population in Singapore found that 35\% of middle-aged participants had multimorbidity [5] and although there are no official estimates in the Singapore primary care setting, the figure is likely to be higher. The prevalence of multimorbidity rises steeply in midlife and plateaus in those aged 75 years and above, [2] and this may be contributed by the growing emphasis on screening and early detection of chronic diseases. In fact, many countries have national health screening programmes [6-8] targeting the middle-age (40-64 years old) population. Thus there is an urgent need for healthcare professionals and policy makers to understand how multimorbidity affects this population.

People with multimorbidity have poorer HrQoL, [9-11] higher healthcare costs and utilization, [12, 13] higher mortality, [14] and reduced work productivity and working performance [15]. However, the impact of multimorbidity may be different across various age groups. While many studies have focused on the elderly, [16-18] few have focused on middle-aged adults. Younger people may have poorer $\mathrm{HrQoL}$ compared to the elderly, possibly due to the lower health expectations of older people or their ability to adapt better to lifestyle changes imposed by adverse health events $[9,11]$. Midlife is the time when chronic illnesses start to surface and often take adults by surprise [19]. Work also plays a large role in the lives of middle-aged adults and is central to their identity [20]. While the midlife period may reflect the peak in professional attainment and earning for many, it is also a period when adults face multiple stresses and burdens such as medical bills, financial loans, caring for dependents, and bereavement [19]. There is an association between stress and self-rated health in midlife, those with poorer health ratings report more stress and less satisfaction in life [21]. By understanding how the co-existence of multiple chronic conditions affects middle-aged patients, suitable interventions can be designed to improve patient care and satisfaction. We aimed to describe the association between multimorbidity and $\mathrm{HrQoL}$ in the middle-aged primary care population in Singapore.

\section{Methods}

A cross-sectional study was conducted in August 2017 at Hougang Polyclinic, which is part of a bigger network of clinics under the National Healthcare Group Polyclinics (NHGP). Hougang polyclinic is a large public primary care centre with approximately 140 healthcare providers including physicians, nurses, pharmacists, and allied health professionals. It provides a comprehensive range of healthcare services, including health screening, treatment for acute and chronic medical conditions, women and child health services, as well as dental care. The polyclinic serves the Hougang Township, the fifth largest township in Singapore, with approximately 223, 010 residents of which $40 \%$ are middle-aged [22].

There is no strict definition of "middle-age" and studies have defined it as age between 40-65 years [23] or 45-64 years $[3,5,24]$ In our study, the lower age limit was defined as 40 years old as that is also the minimum age at which general health screening is recommended [6]. According to the Singapore census those aged 65 years and above are considered elderly [22] and hence the upper limit of our middle-age range was defined as 64 years old.

With assistance from the NHGP Office of Clinical Informatics and clinic operations staff, we obtained the daily lists of middle-aged patients (40-64 years old) with physician appointments. The appointments were either scheduled in advance for regular review of their chronic conditions or scheduled on the same day as a walk-in appointment. Potential participants were selected in a systematic randomized manner based on the time and type (regular review or as walk-in) of appointment. They were then approached and screened for eligibility. The inclusion criteria were a) aged 40-64 years, b) had at least one or more chronic condition(s) out of a predetermined list of 14 chronic conditions, c) consented to access of electronic medical records for data collection, and d) spoke and understood any one of the three main languages in Singapore: English, Mandarin or Malay. Participants were excluded if they were non-communicative, unable to give consent, or if they did not complete the survey. Our study focused on how having chronic conditions affected one's HrQoL and we also excluded those with no chronic conditions as they often present at our polyclinic with acute self-limiting conditions [25] which can transiently affect their HrQoL.

Recruitment and consent-taking were done by trained interviewers, including a research assistant, two medical students, and the principal investigator. The intervieweradministered questionnaires were conducted in a quiet area in the polyclinic.

\section{Definition of multimorbidity}

We defined multimorbidity as the presence of three or more chronic conditions. Although many studies $[3,5,9,10]$ and organisations $[26,27]$ have used a cut-off of two or more chronic conditions to define multimorbidity, some studies $[11,18]$ have used a higher cut-off of three or more conditions. Holzer et al. [28] found a close relationship between the estimated prevalence of two or more conditions and that of three or more conditions, and that both definitions of multimorbidity also gave the same information on prevalence. In an unpublished cross-sectional study [29] of 787, 
466 primary care patients in Singapore, the prevalence of multimorbidity in the middle-aged patients was $45.3 \%$ when the cut-off was two or more conditions. When the cut-off was three or more conditions, the prevalence decreased to 28.5\% [29] For our study, using a higher cut-off to define multimorbidity can better identify patients with increased needs [2] and this is more meaningful in our setting.

Although there is no standardised definition of multimorbidity, using a list of at least 12 chronic conditions resulted in little variation in prevalence estimates of multimorbidity [2] Thus, we used a list of 14 chronic conditions to define multimorbidity: diabetes mellitus, hypertension, lipid disorder, neurological conditions, respiratory diseases, psychiatric conditions, cancer, chronic kidney disease, heart diseases, arthritis, back/neck problems, gastrointestinal diseases, thyroid disease and physical disability. This list was previously used by Quah et al. [16] to measure multimorbidity in elderly patients at a primary healthcare setting and was derived from the Singapore Mental Health Study [30] Participants were asked to report if they had any of the chronic conditions listed above, as told to them by a registered physician. In this study, the number of chronic condition(s) was categorized dichotomously, distinguishing those with one or two conditions from those with three or more conditions i.e. with multimorbidity.

\section{Measurement of health-related quality of life}

HrQoL was measured by EQ5D-3 L questionnaire, [31] which has been validated locally, [32-34] and is available in the three most spoken languages in Singapore- English, Mandarin and Malay. The EQ5D consists of two components. The first component is the health-state Utility Index (UI). It measures five dimensions of HrQoL (mobility, self-care, usual activities, pain/discomfort and anxiety/depression) on a three-point severity scale (no problems, moderate problems or extreme problems). The Singapore time trade-off values were used to convert the information into UI scores, with -0.790 being the worst health state and 1.000 being the best health state. The second component of the EQ5D is the visual analogue scale (VAS) which consists of a scale from 0 to 100. It is used to assess self-perceived global levels of health, with 0 representing the worst imaginable health state and 100 the best imaginable health state. Participants were asked to select a number on the VAS, which best represented their global health state for that day.

\section{Sociodemographic variables}

The sociodemographic variables collected included age, sex, ethnicity, main spoken language, marital status, education level, work status, monthly household income (in Singapore dollars), type of dwelling, home ownership, and living arrangement. With regards to the type of dwelling, the options are more varied in view of Singapore's unique housing landscape where the majority of the population live in subsidised housing provided by the Housing Development Board (HDB). The size and value of these apartments correspond to the number of rooms stated. In addition, there are hybrids of public and private housing such as the Executive Condominiums and Housing Urban Development Company apartments that cost more than the usual HDB apartments. The minority of the population stay in private housing that includes private condominiums and landed properties [22].

\section{Study sample}

Sample size was calculated by assuming a Pearson's coefficient of -0.2 , which was derived from the Spearman coefficient of the association between EQ5D UI and the count of chronic conditions reported in $\mathrm{H}$ Radner et al. [35] With alpha of 0.05 and power (1-beta) of $80 \%$, the estimated sample size was 194 . Assuming $30 \%$ refusal and incomplete data, the final calculated sample size was 278 .

\section{Statistical analysis}

The sociodemographic characteristics, number of chronic conditions, and EQ5D states of the study population were analysed descriptively. Means with standard deviations were calculated for continuous variables, while frequencies and percentages were computed for categorical variables.

A generalised linear model with log link function was used to analyse the associations between multimorbidity and each of the two components (UI and VAS) of the EQ5D, producing regression coefficients with $95 \%$ confidence intervals. Binary logistic regression was used to compare the responses i.e., "moderate or severe problems" to "no problem" for the sub-group analysis of each of the EQ5D domain. The analyses were adjusted for sociodemographic variables. A $p$-value of $<0.05$ was considered statistically significant. All statistical analyses were performed using IBM SPSS for Windows Version 24 (IBM Corporation, Armonk, New York, USA).

\section{Results}

Of the 410 clinic patients who were approached and screened, 46 patients were not eligible and 64 patients declined to participate in the study. Two participants were subsequently excluded as they did not fulfil the inclusion criteria and one participant participated twice on different days where the second survey by the same participant was excluded. A total of 297 participants were included in the study giving a response rate of $72.4 \%$. Most of the participants were aged between 55 to 64 years, with a mean age of $56.6 \pm 5.8$ years. A portion of $41.7 \%$ had three or more conditions i.e. multimorbidity. The participants were mainly males (52.2\%), Chinese 
Table 1 Demographic Characteristics of the participants $(N=297)$

N

\section{Age (years)}

$<50$

50-54

55-59

60-64

Mean $( \pm$ SD)

Median (IQR)

Sex

Male

Female

Ethnicity

Chinese

Non-Chinese

Main Spoken Language

English

Mandarin

Malay/Tamil/Others

Marital Status

Married

Others $^{a}$

Education

Primary/No formal

Secondary

Post-Secondary

Employed Or Not Employed

Employed

Unemployed/Retired

Monthly Household Income

$<\$ 2000$

$\$ 2000-\$ 3999$

$\$ 4000-\$ 5999$

$\geq \$ 6000$

Not disclosed

\section{Dwelling}

Institution/HDB 1-3 room

HDB 4 room

Other dwellings ${ }^{b}$

Home Ownership

Owner-occupied

Not owner-occupied

Living Arrangement

Living alone

Living with others

155

142

$\begin{array}{ll}38 & 12.8 \\ 54 & 18.2 \\ 98 & 33.0 \\ 107 & 36.0 \\ 56.6 & ( \pm 5.8) \\ 58.0 & (53.0-61.0)\end{array}$

52.2

47.8

${ }^{\mathrm{a}}$ Other marital status: single, widowed, divorced, and separated

${ }^{b}$ Other dwellings: HDB 5-room or executive apartment, Housing and Urban Development Company apartment, HDB executive condominium, private condominium, and landed properties $H D B$ Housing and Development Board 
(81.5\%), married (78.1\%), and employed (70.0\%) (Table 1). The mean number of chronic conditions was $2.28 \pm 1.2$ and the most common conditions were lipid disorder (61.3\%), hypertension (57.2\%) and diabetes mellitus (34.3\%).

All the participants completed the EQ5D questionnaire and the mean EQ5D UI and VAS were $0.843 \pm$ 0.223 and $66.9 \pm 16.4$ respectively. There were 23 health states represented out of 243 possible ones from the study population. The most common (49.2\%) EQ5D UI was 1.000 , which corresponded to the best achievable health state of "11111", representing "no problem" with all five domains. The lowest EQ5D UI was - 0.357 which corresponded to a health state of "23222" i.e., "severe problems" with self-care and "moderate problems" with mobility, usual activities, anxiety/depression, and pain/ discomfort. The EQ5D domain with the most reported problem was pain/discomfort (41.0\%), followed by anxiety/depression (22.9\%), mobility (13.5\%), activities of daily living (9.8\%), and self-care respectively (0.34\%). Compared to participants with one or two conditions, those with three or more conditions, i.e. with multimorbidity, had higher odds ( $\mathrm{OR}=2.04, p=0.01)$ of reporting problems with pain/discomfort (Table 2).

Participants with three or more conditions, i.e. with multimorbidity, had lower EQ5D UI and VAS scores compared to those with one or two conditions. However, after adjusting for sociodemographic factors, only EQ5D UI was significantly associated with the number of chronic conditions $(\beta$-coefficient $=-0.064, p=0.04)(\mathrm{Ta}-$ bles 3 and 4). In the same regression model, age and living arrangement were also associated with EQ5D UI. Participants aged less than 50 years old and those living with others had lower EQ5D UI compared to those aged 60 to 64 years old ( $\beta$-coefficient $=-0.137, p=0.01$ ), and those living alone $(\beta$-coefficient $=-0.151, p=0.02)$, respectively (Table 3 ).

\section{Discussion}

We conducted a cross-sectional study investigating the association between multimorbidity and HrQoL in middleaged patients at a primary care setting in Singapore. In the study, participants with multimorbidity had significantly lower domain-specific HrQoL scores (EQ5D UI) but not global HrQoL scores (VAS). Specifically, participants reported more problems with the domain of pain/ discomfort.

Middle-aged patients with multimorbidity had lower EQ5D UI, and is in keeping with the findings from other studies $[9,11,36]$. Multimorbidity increases the disease burden and affects one's HrQoL. Additionally, patients with multimorbidity are more likely to experience higher treatment burden which includes polypharmacy, adjustment to major lifestyle changes, constant monitoring of one's own health status, and navigation of a complex healthcare system [26, 37, 38]. Middle-aged adults also often have multiple financial and care-giving responsibilities $[19,21]$ which may be overwhelming for them to balance these responsibilities with their own healthcare needs.

Although patients with multimorbidity had lower EQ5D VAS in our study, the association was not statistically significant. This is in contrast to other studies in the primary care [39] and general populations [40] that reported an inverse relationship between multimorbidity and VAS scores. The EQ5D UI is based on the participants' selection of one out of three responses to each of the five EQ5D domains that is weighted by general public preferences. In contrast, the VAS is derived from the participants' self-indication of their general health for that day. Compared to the choice-based UI, the VAS measures a broader construct of the individual's health which is not confined to the five specific domains and is more reflective of the individual's perception of his or her own general health state [41]. This study suggested that while multimorbidity was associated with poorer HrQoL compared to those without multimorbidity, as measured by a composite of pain, physical functioning, and mental wellbeing in the middle-aged participants, it was not associated with the general health state. When considering their general health state, the participants could have perceived their chronic conditions as mild, with little impact on their lives. While illness perception has been associated with HrQoL in single diseases, [42, 43] its influence on HrQoL in patients with multimorbidity is not well studied. Further studies are required to understand the association of patients' illness perceptions with multimorbidity and their HrQoL.

Another interesting finding in our study was the significant association between multimorbidity and the EQ5D domain of pain/discomfort. The domain of pain/

Table 2 Adjusted ORs of participants reporting "Moderate or Severe problems" across each of the 5 EQ5D domains

\begin{tabular}{|c|c|c|c|c|c|c|c|c|c|}
\hline \multicolumn{2}{|l|}{ Mobility } & \multicolumn{2}{|l|}{ Self-care } & \multicolumn{2}{|c|}{ Activities of daily living } & \multicolumn{2}{|l|}{ Pain / discomfort } & \multicolumn{2}{|l|}{ Mood } \\
\hline Adjusted OR (C.I) & $\overline{p \text {-value }}$ & Adjusted OR (C.I) & $\overline{p \text {-value }}$ & Adjusted OR (C.I) & $\overline{p \text {-value }}$ & Adjusted OR (C.I) & $p$-value & Adjusted OR (C.I) & $p$-value \\
\hline $1.41(0.69-2.89)$ & 0.35 & $-^{c}$ & $-^{c}$ & $1.37(0.57-3.29)$ & 0.48 & $2.04(1.22-3.40)$ & $0.01^{*}$ & $1.06(0.58-1.91)$ & 0.86 \\
\hline
\end{tabular}

Adjusted for age, gender, ethnicity, language, marital status, education, employment, household income, dwelling, home ownership and living arrangement

"Unadjusted OR for the domain of self-care domain is $13,133,941.80$, as all participants without multimorbidity reported "No problems" with self-care, while only 1 participant with multimorbidity reported "Moderate problems" with self-care

${ }^{*} p$-value $<0.05$ 
Table 3 Unadjusted and adjusted means, and $\beta$ coefficients of EQ5D UI across various predictors

\begin{tabular}{|c|c|c|c|c|c|c|c|}
\hline Predictor Variables & Un adjusted mean & $(\mathrm{SD})$ & Adjusted mean & (SD) & $\beta$ & $95 \%$ C.I & $p$-value \\
\hline \multicolumn{8}{|l|}{ No. of chronic condition(s) } \\
\hline 1 or 2 & 0.871 & $(0.198)$ & 0.837 & $(0.034)$ & REFERENCE & - & - \\
\hline$\geq 3$ & 0.804 & $(0.251)$ & 0.785 & $(0.032)$ & -0.064 & $(-0.125,-0.003)$ & $0.04^{*}$ \\
\hline \multicolumn{8}{|l|}{ Age (years) } \\
\hline$<50$ & 0.754 & $(0.304)$ & 0.737 & $(0.042)$ & -0.137 & $(-0.246,-0.029)$ & $0.01^{*}$ \\
\hline $50-54$ & 0.846 & $(0.217)$ & 0.837 & $(0.042)$ & -0.01 & $(-0.095,0.075)$ & 0.82 \\
\hline $55-59$ & 0.845 & $(0.222)$ & 0.828 & $(0.036)$ & -0.021 & $(-0.091,0.050)$ & 0.57 \\
\hline 60-64 & 0.871 & $(0.187)$ & 0.845 & $(0.036)$ & REFERENCE & - & - \\
\hline \multicolumn{8}{|l|}{ Sex } \\
\hline Male & 0.843 & $(0.224)$ & 0.801 & $(0.035)$ & REFERENCE & - & - \\
\hline Female & 0.843 & $(0.224)$ & 0.82 & $(0.032)$ & 0.023 & $(-0.040,0.087)$ & 0.48 \\
\hline \multicolumn{8}{|l|}{ Ethnicity } \\
\hline Chinese & 0.854 & $(0.212)$ & 0.845 & $(0.034)$ & REFERENCE & - & - \\
\hline Non-Chinese & 0.795 & $(0.265)$ & 0.777 & $(0.037)$ & -0.084 & $(-0.174,0.005)$ & 0.06 \\
\hline \multicolumn{8}{|l|}{ Main spoken language } \\
\hline English & 0.86 & $(0.249)$ & 0.837 & $(0.036)$ & REFERENCE & - & - \\
\hline Mandarin & 0.835 & $(0.214)$ & 0.778 & $(0.034)$ & -0.073 & $(-0.148,0.001)$ & 0.05 \\
\hline Malay/Tamil/ Others & 0.838 & $(0.206)$ & 0.817 & $(0.040)$ & -0.025 & $(-0.116,0.066)$ & 0.59 \\
\hline \multicolumn{8}{|l|}{ Marital status } \\
\hline Married & 0.856 & $(0.206)$ & 0.845 & $(0.038)$ & REFERENCE & - & - \\
\hline Others $^{a}$ & 0.797 & $(0.275)$ & 0.777 & $(0.034)$ & -0.084 & $(-0.171,0.003)$ & 0.06 \\
\hline \multicolumn{8}{|l|}{ Education } \\
\hline Primary/ No formal & 0.835 & $(0.218)$ & 0.807 & $(0.038)$ & REFERENCE & - & - \\
\hline Secondary & 0.843 & $(0.239)$ & 0.814 & $(0.036)$ & 0.009 & $(-0.066,0.083)$ & 0.82 \\
\hline Post-secondary & 0.851 & $(0.205)$ & 0.811 & $(0.035)$ & 0.005 & $(-0.087,0.097)$ & 0.91 \\
\hline \multicolumn{8}{|l|}{ Employment } \\
\hline Employed & 0.847 & $(0.217)$ & 0.83 & $(0.032)$ & REFERENCE & - & - \\
\hline Unemployed/ Retired & 0.832 & $(0.239)$ & 0.792 & $(0.036)$ & -0.047 & $(-0.116,0.022)$ & 0.18 \\
\hline \multicolumn{8}{|l|}{ Monthly Household Income } \\
\hline$<\$ 2000$ & 0.828 & $(0.284)$ & 0.807 & $(0.037)$ & REFERENCE & - & - \\
\hline$\$ 2000-\$ 3999$ & 0.861 & $(0.193)$ & 0.831 & $(0.038)$ & 0.03 & $(-0.059,0.119)$ & 0.51 \\
\hline$\$ 4000-\$ 5999$ & 0.808 & $(0.242)$ & 0.791 & $(0.041)$ & -0.02 & $(-0.120,0.079)$ & 0.69 \\
\hline$\geq \$ 6000$ & 0.866 & $(0.186)$ & 0.812 & $(0.045)$ & 0.006 & $(-0.100,0.113)$ & 0.91 \\
\hline Not disclosed & 0.848 & $(0.202)$ & 0.811 & $(0.038)$ & 0.005 & $(-0.090,0.100)$ & 0.92 \\
\hline \multicolumn{8}{|l|}{ Dwelling } \\
\hline Institution/ HDB 1-3 room & 0.841 & $(0.247)$ & 0.824 & $(0.035)$ & REFERENCE & - & - \\
\hline HDB 4 room & 0.822 & $(0.222)$ & 0.791 & $(0.036)$ & -0.041 & $(-0.122,0.040)$ & 0.32 \\
\hline Other dwellings $s^{b}$ & 0.87 & $(0.207)$ & 0.817 & $(0.038)$ & -0.009 & $(-0.096,0.079)$ & 0.85 \\
\hline \multicolumn{8}{|l|}{ Home Ownership } \\
\hline Owner-occupied & 0.855 & $(0.211)$ & 0.842 & $(0.029)$ & REFERENCE & - & - \\
\hline Not owner-occupied & 0.743 & $(0.296)$ & 0.78 & $(0.045)$ & -0.077 & $(-0.192,0.037)$ & 0.19 \\
\hline \multicolumn{8}{|l|}{ Living arrangement } \\
\hline Living alone & 0.919 & $(0.129)$ & 0.874 & $(0.054)$ & REFERENCE & - & - \\
\hline Living with others & 0.837 & $(0.228)$ & 0.751 & $(0.024)$ & -0.151 & $(-0.274,-0.028)$ & $0.02^{*}$ \\
\hline
\end{tabular}

\footnotetext{
a Other marital status: not married, single, widowed, divorced, and separated
}

${ }^{b}$ Other dwellings: HDB 5-room, HDB executive, Housing and Urban Development Company apartment, HDB executive condominium, private condominium, and landed properties

$H D B$ Housing and Development Board

${ }^{*} p$-value $<0.05$ 
Table 4 Unadjusted and adjusted means, and $\beta$ coefficients of EQ5D VAS across various predictors

\begin{tabular}{|c|c|c|c|c|c|c|c|}
\hline Predictor Variables & Un adjusted mean & (SD) & Adjusted mean & (SD) & $\beta$ & $95 \%$ C.I & $p$-value \\
\hline \multicolumn{8}{|l|}{ No. of chronic condition(s) } \\
\hline 1 or 2 & 68.5 & $(16.0)$ & 69.6 & $(2.5)$ & REFERENCE & - & - \\
\hline$\geq 3$ & 64.9 & $(16.8)$ & 66.5 & $(2.5)$ & -0.045 & $(0.102,0.12)$ & 0.12 \\
\hline \multicolumn{8}{|l|}{ Age (years) } \\
\hline$<50$ & 62.8 & $(19.1)$ & 63.2 & $(3.2)$ & -0.100 & $(-0.199 .-0.001)$ & 0.05 \\
\hline $50-54$ & 68.8 & $(16.2)$ & 71.4 & (3.3) & 0.021 & $(-0.058,0.101)$ & 0.60 \\
\hline $55-59$ & 66.5 & $(16.8)$ & 68.0 & $(2.7)$ & -0.027 & $(-0.095,0.041)$ & 0.43 \\
\hline $60-64$ & 68.0 & $(15.0)$ & 69.9 & $(2.7)$ & REFERENCE & - & - \\
\hline \multicolumn{8}{|l|}{ Sex } \\
\hline Male & 66.8 & $(16.1)$ & 67.8 & $(2.6)$ & REFERENCE & - & - \\
\hline Female & 67.1 & $(16.7)$ & 68.3 & $(2.4)$ & 0.006 & $(0.053,0.066)$ & 0.84 \\
\hline \multicolumn{8}{|l|}{ Ethnicity } \\
\hline Chinese & 66.8 & $(16.2)$ & 67.4 & $(2.5)$ & REFERENCE & - & - \\
\hline Non-Chinese & 67.9 & $(17.5)$ & 68.7 & $(2.9)$ & 0.019 & $(0.064,0.101)$ & 0.66 \\
\hline \multicolumn{8}{|l|}{ Main Spoken Language } \\
\hline English & 67.4 & $(16.3)$ & 69.4 & $(2.8)$ & REFERENCE & - & - \\
\hline Mandarin & 66.4 & $(16.4)$ & 66.8 & $(2.7)$ & -0.038 & $(-0.110,0.034)$ & 0.31 \\
\hline Malay/Tamil/ Others & 67.8 & (16.9) & 68.0 & $(3.1)$ & -0.021 & $(-0.106,0.065)$ & 0.64 \\
\hline \multicolumn{8}{|l|}{ Marital Status } \\
\hline Married & 67.3 & $(16.0)$ & 68.7 & $(2.8)$ & REFERENCE & - & - \\
\hline Others $^{a}$ & 65.8 & $(18.0)$ & 67.4 & $(2.6)$ & -0.018 & $(-0.097,0.061)$ & 0.65 \\
\hline \multicolumn{8}{|l|}{ Education } \\
\hline Primary/ No formal & 67.8 & (16.4) & 70.1 & (3.0) & REFERENCE & - & - \\
\hline Secondary & 67.3 & $(15.7)$ & 68.6 & $(2.8)$ & -0.022 & $(-0.091,0.048)$ & 0.54 \\
\hline Post-secondary & 65.5 & $(17.7)$ & 65.5 & (2.6) & -0.068 & $(-0.156,0.020)$ & 0.13 \\
\hline \multicolumn{8}{|l|}{ Employment } \\
\hline Employed & 67.1 & $(16.5)$ & 68.6 & $(2.4)$ & REFERENCE & - & - \\
\hline Unemployed/ Retired & 66.7 & (16.3) & 67.5 & $(2.7)$ & -0.016 & $(-0.081,0.049)$ & 0.62 \\
\hline \multicolumn{8}{|l|}{ Monthly Household Income } \\
\hline$<\$ 2000$ & 64.7 & $(18.0)$ & 64.8 & $(2.8)$ & REFERENCE & - & - \\
\hline$\$ 2000-\$ 3999$ & 68.8 & $(14.6)$ & 70.4 & $(2.9)$ & 0.083 & $(-0.002,0.168)$ & 0.06 \\
\hline$\$ 4000-\$ 5999$ & 66.0 & $(18.0)$ & 68.2 & $(3.2)$ & 0.051 & $(-0.042,0.144)$ & 0.28 \\
\hline$\geq \$ 6000$ & 68.6 & $(14.9)$ & 70.7 & (3.6) & 0.087 & $(-0.015,0.189)$ & 0.09 \\
\hline Not disclosed & 66.5 & $(16.7)$ & 66.4 & $(2.9)$ & 0.025 & $(-0.066,0.116)$ & 0.59 \\
\hline \multicolumn{8}{|l|}{ Dwelling } \\
\hline Institution/ HDB 1-3 room & 68.9 & $(19.0)$ & 70.0 & $(2.7)$ & REFERENCE & - & - \\
\hline HDB 4 room & 65.1 & $(16.1)$ & 65.9 & $(2.7)$ & -0.061 & $(-0.135,0.013)$ & 0.11 \\
\hline Other dwellings ${ }^{b}$ & 67.9 & $(14.6)$ & 68.3 & $(2.9)$ & -0.026 & $(-0.106,0.054)$ & 0.53 \\
\hline \multicolumn{8}{|l|}{ Home Ownership } \\
\hline Owner-occupied & 67.2 & (15.8) & 68.9 & $(2.3)$ & REFERENCE & - & - \\
\hline Not owner-occupied & 64.7 & $(21.2)$ & 67.2 & (3.4) & -0.026 & $(-0.127,0.076)$ & 0.62 \\
\hline \multicolumn{8}{|l|}{ Living Arrangement } \\
\hline Living alone & 70.3 & (21.7) & 71.0 & $(4.1)$ & REFERENCE & - & - \\
\hline Living with others & 66.7 & $(16.0)$ & 65.2 & $(1.9)$ & -0.086 & $(-0.204,0.033)$ & 0.16 \\
\hline
\end{tabular}

ather marital status: not married, single, widowed, divorced, and separated

${ }^{b}$ Other dwellings: HDB 5-room, HDB executive, Housing and Urban Development Company apartment, HDB executive condominium, private condominium, and landed properties

$H D B$ Housing and Development Board

${ }^{*} p$-value $<0.05$ 
discomfort has the highest percentage of reported problems in our study and this is similar to other studies [12, $36,39,44$ ] Chronic pain is a common, complex, and challenging condition and the extent to which multimorbidity is associated with chronic pain in the middle-aged population is unknown. A cross-sectional analysis of the elderly MultiCare Cohort Study sample found that chronic pain, as measured by the Graded Chronic Pain Scale [45] was largely associated with chronic lower back problems [17] In our study, we were not able to distinguish if participants who reported problems to pain/discomfort had chronic or acute pain, neither were we able to determine the cause(s) of the participants' pain/discomfort. One may suffer from pain caused by the side-effects of medications, or from the discomfort caused by the disease(s). Moreover, chronic pain is strongly influenced by demographic and psychosocial factors [46] Future studies may be undertaken to evaluate the factors contributing to chronic pain and HrQoL in middle-aged patients with multimorbidity. This can contribute to subsequent interventions to improve $\mathrm{HrQoL}$ in this population.

One significant observation is that our sample is slightly older compared to other middle-aged primary care populations, $[3,15,24]$ with most of our patients aged between 55 and 64 years old. This is reflective of the middle-age distribution at our centre as well as the fast-ageing Singaporean population [22] Within our study population participants below 50 years of age had poorer HrQoL compared to those aged 60 years and above, a finding similar to that by Peters et al. [47] Possible explanations include the burden of additional responsibilities such as work or caring for children and elderly parents, and the higher likelihood of younger people reporting mental health problems which may have affected the EQ5D UI [47]. However, the adaptability of patients to the onset of new conditions and different chronic disease trajectories may change with time [47]. We also found that participants living with others had lower HrQoL compared to those living alone. Middle-aged patients with multimorbidity may face additional stress from caring for dependents, who would most likely be staying with them. Prazeres et al. [48] also showed that living arrangement may affect both the physical and mental components of HrQoL in patients with multimorbidity.

Finally, it is important to note that we used a higher cut-off of three or more conditions to define multimorbidity in this study. Patients with two chronic conditions that are considered as multimorbid in other studies are considered as non-multimorbid in our study. Although there is currently no standardized definition of multimorbidity, most authors use a cut-off of two or more conditions [28]. There are exceptions with some studies $[11,18]$ using a cut-off of three or more, especially when the prevalence of multimorbidity in the study population is high. Harrison et al. [4] found that by using a cut-off of two or more conditions, one in two primary care patients would be diagnosed with multimorbidity, whereas using a higher cut-off of three or more would decrease the estimate to one in four. This was also reflected in an unpublished study in our local primary care setting [29]. Using a lower cut-off may identify such a high proportion of patients as having multimorbidity that the measure lacks specificity to be useful, $[2,4]$ hence we decided on a higher cut-off as this will enable us to identify patients with higher needs.

\section{Strengths and limitations}

This study has a few limitations. Firstly, the crosssectional nature does not allow establishment of causal relationships. Secondly, as the study was done at a single polyclinic, there was slight over-representation of Chinese and under-representation of Malays and Indians compared to the national population. Thirdly, the data collected were self-reported and there may be under or overreporting of chronic medical conditions $[49,50]$ Fourthly, we did not include patients with no chronic conditions in our study. The focus of our study was on how having chronic conditions can affect HrQoL and such patients often present at our clinic with acute self-limiting conditions [25] which may transiently affect their HrQoL without any meaningful long term impact.

The strengths of our study include the administration of the study questionnaires in multiple languages to maximize sample representativeness, and the selection of a validated $\mathrm{HrQoL}$ measure with local HrQoL weights. In addition, our study used a systematic randomized sampling method to select potential participants as an attempt to better represent the primary care population.

\section{Conclusion}

This study showed that multimorbidity, as measured by a count of chronic conditions, was not associated with self-perceived global HrQoL but was negatively associated with domain specific HrQoL, specifically for the domain of pain/discomfort. Further studies exploring chronic pain in the middle-aged primary care population with multimorbidity can help physicians better manage pain and improve the HrQoL in this population.

\section{Abbreviations}

EQ5D-3L: EuroQol 5 dimensions -3 levels; HDB: Housing Development Board; HrQoL: Health-related quality of life; UI: Utility Index; VAS: Visual Analogue Scale

\section{Acknowledgements}

We extend our gratitude to Euro Qol for allowing us to use the EQ5D questionnaire. Additionally we would like to thank Kyreen Lee Cheng Ting, Judith Goh, and Zul Hakim for carrying out the field work and supporting the logistics of our study. 


\section{Authors' contributions}

SZ Sim was responsible for carrying out the literature review, designing the study, collecting the data, carrying out statistical analysis, interpreting the data, and writing the manuscript. ES Lee was responsible for designing the study, supervising the conduct of the study, interpreting the data and revising the manuscript. HL Koh was responsible for carrying out statistical analysis, interpreting the data, and revising the manuscript. SPS Lee was responsible for interpreting the data and revising the manuscript. DYL Young assisted in the design of the study and the revision of the manuscript. All authors have read and approved the final manuscript.

\section{Funding}

The study was funded by the FY2017 National Healthcare Group -Lee Kong Chian Medicine Clinician-Scientist Preparatory Programme Award (Reference: CSPP-17001), which was not involved in the design of the study and collection, analysis, and interpretation of data and in writing the manuscript.

\section{Availability of data and materials}

The datasets generated and/or analysed during the current study are not publicly available but are available from the corresponding author on reasonable request.

\section{Ethics approval and consent to participate}

The study protocol was approved by the National Healthcare Group Domain Specific Review Board in May 2017 (Reference: 2016/01280). Written informed consent was obtained from all participants prior to their participation in the study.

\section{Consent for publication}

Not applicable.

\section{Competing interests}

The authors declare no conflict of interest.

\section{Author details}

${ }^{1}$ Clinical Research Unit, National Healthcare Group Polyclinics, 3 Fusionopolis Link, Nexus@one-north. South Tower, \# 05-10, Singapore 138543, Singapore. 2Division of Family Medicine, Yong Loo Lin School of Medicine, National University of Singapore, NUHS Tower Block, 1E Kent Ridge Road Level 11, Singapore 119228, Singapore.

Received: 13 February 2020 Accepted: 2 September 2020

Published online: 14 September 2020

\section{References}

1. van den Akker M, Buntinx F, Knottnerus JA. Comorbidity or multimorbidity. Eur J Gen Pract. 2009:2(2):65-70.

2. Fortin M, Stewart M, Poitras M-E, Almirall J, Maddocks H. A systematic review of prevalence studies on multimorbidity: toward a more uniform methodology. Ann Fam Med. 2012;10(2):142-51.

3. Barnett K, Mercer SW, Norbury M, Watt G, Wyke S, Guthrie B. Epidemiology of multimorbidity and implications for healthcare, research, and medical education: a cross-sectional study. Lancet. 2012;380:37-43.

4. Harrison $\mathrm{C}$, Britt $\mathrm{H}$, Miller $\mathrm{G}$, Henderson J. Examining different measures of multimorbidity, using a large prospective cross-sectional study in Australian general practice. BMJ Open. 2014;4:e004694.

5. Ge L, Yap CW, Heng BH. Sex differences in associations between multimorbidity and physical function domains among community-dwelling adults in Singapore. PLoS One. 2018;13(5):e0197443.

6. Ministry of Health Singapore. Enhanced Screen for Life. 2019. Available from https://www.moh.gov.sg/cost-financing/healthcare-schemes-subsidies/ enhanced-screen-for-life Accessed 12 Dec 2019.

7. National Health Service. NHS Screening. 2018. Available from https://www nhs.uk/conditions/nhs-screening. Accessed 12 Dec 2019.

8. Australian Government Department of Health. Population Based Screening Framework. 2019. Available from http://www.cancerscreening.gov.au/ internet/screening/publishing.nsf/Content/population-based-screeningframework. Accessed 12 Dec 2019.

9. Mujica-Mota RE, Roberts M, Abel G, Elliott M, Lyratzopoulos G, Roland M, et al. Patterns of morbidity and multi-morbidity and their impact on health- related quality of life: evidence from a national survey. Qual Life Res. 2015; 24(4):909-18.

10. Hopman P, Schellevis FG, Rijken M. Health-related needs of people with multiple chronic diseases: differences and underlying factors. Qual Life Res. 2015;25(3):651-60

11. N'Goran AA, Déruaz-Luyet A, Haller DM, Zeller A, Rosemann T, Streit S, et al. Comparing the self-perceived quality of life of multimorbid patients and the general pulation using the EQ-5D-3L. PLoS One. 2017;12(12):e0188499.

12. Hopman P, Heins MJ, Rijken M, Schellevis FG. Health care utilization of patients with multiple chronic diseases in the Netherlands: differences and underlying factors. Eur J Intern Med. 2015;26(3):190-6.

13. Glynn LG, Valderas JM, Healy P, Burke E, Newell J, Gillespie P, et al. The prevalence of multimorbidity in primary care and its effect on health care utilization and cost. Fam Pract. 2011;28(5):516-23.

14. Willadsen TG, Siersma V, Nicolaisdóttir DR, Køster-Rasmussen R, Jarbøl DE, Reventlow S, et al. Multimorbidity and mortality: A 15-year longitudinal registry-based nationwide Danish population study. J Comorb. 2018;8(1): $2235042 \times 18804063$

15. Sum G, Ishida M, Koh GCH, Singh A, Oldenburg B, Lee JT. Implications of multimorbidity on healthcare utilisation and work productivity by socioeconomic groups: cross-sectional analyses of Australia and Japan. PLoS One. 2020;15(4):e0232281.

16. Quah JHM, Wang P, Ng RRG, Luo N, Tan NC. Health-related quality of life of older Asian patients with multimorbidity in primary care in a developed nation. Geriatr Gerontol Int. 2017;17(10):1429-37.

17. Scherer M, Hansen H, Gensichen J, Mergenthal K, Riedel-Heller S, Weverer S, et al. Association between multimorbidity patterns and chronic pain in elderly primary care patients: a cross-sectional observational study. BMC Fam Pract. 2016;17:68

18. van den Bussche $H$, Koller D, Kolonko $T$, Hansen $H$, Wegscheider K, Glaeske $G$ et al. Which chronic diseases and disease cdombinations are specific to multimorbidity in the elderly? Results of a claims data based cross-sectional study in GermanyBMC Public Health 2011;11:101.

19. Lachman ME, Teshale S, Agrigoroaei S. Midlife as a pivotal period in the life course: balancing growth and decline at the crossroads of youth and old age. Int J Behav Dev. 2015:39(1):20-31.

20. Sterns $H L$, Huyck MH. The role of work in midlife. In: Lachman ME, editor. Handbook of midlife development. New York: Wiley; 2001. p. 447-86.

21. Aldwin C, Levenson M. Stress, coping, and health at midlife: a developmental perspective. In: Lachman ME, editor. Handbook of midlife development. New York: Wiley; 2001. p. 188-214.

22. Department of Statistics Singapore. Government of Singapore. 2020. https:// www.singstat.gov.sg. Accessed 17 Jan 2020.

23. Kanesarajah J, Waller M, Whitty JA, Mishra GD. Multimorbidity and quality of life at mid-life: a systematic review of general population studies. Maturitas. 2018 Mar;109:53-62.

24. Bao XY, Xie YX, Zhang XX, Peng X, Huang JX, Du QF, et al. The association between multimorbidity and health-related quality of life: a cross-sectional survey among community middle-aged and elderly residents in southern China. Health Qual Life Outcomes. 2019 Jun 24;17(1):107.

25. Health Information Division. Primary Care Survey 2014. Singapore: Ministry of Health Singapore; 2014.

26. World Health Organization (WHO). Multimorbidity: Technical Series On Safer Primary Care. Geneva: WHO; 2016.

27. Le Reste JY, Nabbe P, Rivet C, Lygidakis C, Doerr C, Czachowski S, et al. The European general practice research network presents the translations of its comprehensive definition of multimorbidity in family medicine in ten European languages. PLoS One. 2015;10(1):e0115796.

28. Holzer BM, Siebenhuener K, Bopp M, Minder CE. Overcoming cut-off restrictions in multimorbidity prevalence estimates. BMC Public Health. 2014; $14: 780$

29. Lee ES. Measuring multimorbidity [dissertation]. Ontario: Western University; 2019

30. Subramaniam M, Abdin E, Vaigankar JA, Luo N, Heng D, McCrone $P$, et al. Impact of psychiatric disorders and chronic physical conditions on healthrelated quality of life: Singapore mental health study. J Affect Disord. 2013; 147:325-30

31. EuroQol Research Foundation. EQ-5D-3L. 2020. Available from: https:// euroqol.org/eq-5d-instruments/eq-5d-3l-about. Accessed 21 Jan 2020.

32. Luo N, Chew LH, Fong KY, Koh DR, Ng SC, Yoon KH, et al. Validity and reliability of the EQ-5D self-report questionnaire in Chinese-speaking 
patients with rheumatic diseases in Singapore. Ann Acad Med Singap. 2003; 32(5):685-90.

33. Wee HL, Loke WC, Li SC, Fong KY, Cheung YB, Machin D, et al. Cross-cultural adaptation and validation of Singapore Malay and Tamil versions of the EQ5D. Ann Acad Med Singap. 2007;36(6):403-8.

34. Gao F, Ng GY, Cheung YB, Thumboo J, Pang G, Koo WH, et al. The Singaporean English and Chinese versions of the EQ-5D achieved measurement equivalence in cancer patients. J Clin Epidemiol. 2009;62(2): 206-13.

35. Radner H, Yoshida K, Mjaavatten MD, Aletaha D, Frits M, Bing L, et al. Development of a multimorbidity index: impact on quality of life using a rheumatoid arthritis cohort. Semin Arthritis Rheum. 2015;45(2):167-73.

36. Millá-Perseguer M, Guadalajara-Olmeda N, Vivas-Consuelo D, UsóTalamantes R. Measurement of health-related quality by multimorbidity groups in primary health care. Health Qual Life Outcomes. 2019:17(1):8.

37. Rosbach M, Andersen JS. Patient-experienced burden of treatment in patients with multimorbidity - a systematic review of qualitative data. PLoS One. 2017;12(6):e0179916.

38. Gray AM, Clarke P, Wolstenholme J, Wordsworth S. Measuring, valuing, and analysing health outcomes. In: Gray AM, Clarke P, Wolstenholme J, Wordsworth S, editors. Applied methods of cost-effectiveness analysis in healthcare. NY: Oxford University Press; 2011. p. 83-118.

39. Heyworth IT, Hazell ML, Linehan MF, Frank TL. How do common chronic conditions affect health-related quality of life? Br J Gen Pract. 2009:59(568):e353-8.

40. Taype-Rondan A, Abbs ES, Lazo-Porras M, Checkley W, Gilman RH, Smeeth L, et al. Association between chronic conditions and health-related quality of life: differences by level of urbanization in Peru. Qual Life Res. 2017;26(12): 3439-47.

41. Feng Y, Parkin D, Devlin NJ. Assessing the performance of the EQ-VAS in the NHS PROMs programme. Qual Life Res. 2014;23:977-89.

42. French DP, Lewin RJP, Watson N, Thompson DR. Do illness perceptions predict attendance at cardiac rehabilitation and quality of life following myocardial infarction? J Psychosom Res. 2005;59:315-22.

43. Weldam SW, Lammers JW, Heijmans MJ, Schuurmans MJ. Perceived quality of life in chronic obstructive pulmonary disease patients: a cross-sectional study in primary care on the role of illness perceptions. BMC Fam Pract. 2014;15:140

44. Tyack Z, Kuys S, Cornwell P, Frakes KA, McPhail S. Health-related quality of life of people with multimorbidity at a community-based, interprofessional student-assisted clinic: implications for assessment and intervention. Chronic |lln. 2018;14(3):169-81.

45. Von Korff M, Ormel J, Keefe FJ, Dworkin SF. Grading the severity of chronic pain. Pain. 1992:50:133-49.

46. Ajgp Bruggink L, Hayes C, Lawrence G, Brain K, Holliday S. Chronic pain overlap and specificity in multimorbidity management. Aust J Gen Pract. 2019 Oct;:48(10):689-92.

47. Peters M, Kelly L, Potter CM, Jenkinson C, Gibbons E, Forder J, et al. Quality of life and burden of morbidity in primary care users with multimorbidity. Patient Relat Outcome Meas. 2018 Feb 16;9:103-13.

48. Prazeres F, Santiago L. Relationship between health-related quality of life, perceived family support and unmet health needs in adult patients with multimorbidity attending primary care in Portugal: a multicentre crosssectional study. Health Qual Life Outcomes. 2016;14(1):156.

49. Baker M, Stabile M, Deri C. What do self-reported, objective, measures of health measure? J Hum Resour. 2004;39(4):1067-93.

50. Johnston DW, Propper C, Shields MA. Comparing subjective and objective measures of health: evidence from hypertension for the income/health gradient. J Health Econ. 2009;28(3):540-52

\section{Publisher's Note}

Springer Nature remains neutral with regard to jurisdictional claims in published maps and institutional affiliations.

Ready to submit your research? Choose BMC and benefit from:

- fast, convenient online submission

- thorough peer review by experienced researchers in your field

- rapid publication on acceptance

- support for research data, including large and complex data types

- gold Open Access which fosters wider collaboration and increased citations

- maximum visibility for your research: over $100 \mathrm{M}$ website views per year

At BMC, research is always in progress.

Learn more biomedcentral.com/submissions 